\title{
Design and Construction of 4-DOF EMG-Based Robot Arm System
}

\author{
Fariz Ali, Junior Sintar, MohdShahrieelMohd Aras, Ahmad ZakiShukor
}

\begin{abstract}
Electromyography (EMG) provides an alternative way of providing signal responses from the muscle. As such, the recent trend in developing myoelectric devices has spark the interest in this specific field of study. This is because the traditional controllers lack in certain parts which reduce the utilization of limbs to control devices mainly the robotic arm. However, noise such as crosstalk, motion artifact, ambient noise and inherent noise have become a major issue when handling EMG signals. The preparation of electromyography requires more attention in terms of muscle group selection, electrode placement and condition of the surrounding as it will affect the signal output. The aim of this project is to develop a 4 degree-offreedom (DOF) robotic arm that can be controlled using EMG signals. The correlation between the EMG signal and the robotic arm are required to be identified in order to analyze the performance of robotic arm. Review on the actuator, electromyography methods and microcontroller are done to evaluate the techniques used from past researches. The methods of this project include hardware development of robotics arm, development of forward kinematic, sensor calibration and electrode positioning and experiment on classification and validation of EMG signals based on hand gestures. The experiment showed that the sampling rate and arm position affect the EMG signal output. In addition, the controllability of the robotic arm was low because the motors are controlled independently. The objective of the project has been achieved as the EMG-controlled robotic arm has been successfully developed. The robotic arm is still available for improvement by adding multiple channel sensors and implementing a wireless system.
\end{abstract} arm.

Keywords: Electromyography, EMG signal, muscle, robotic

\section{INTRODUCTION}

Electromyography (EMG) has been commonly used in biomedical, clinical and also modern human computer interaction. EMG is a process of measuring electrical activity in the muscles. An EMG [1] is basically the summation of all the action potential recorded using electrodes from the muscle fiber. The motor units [2] which is made up of muscle fiber exhibits electrical properties when muscles undergoes contraction. The acquisition of EMG signals would help in providing useful information from the Motor Unit Action Potential (MUAP) for the application of modern technologies.

Revised Manuscript Received on October 23, 2019.

Fariz Ali, Mechatronics Department, Faculty of Electrical Engineering, Universiti Teknikal Malaysia Melaka (UTeM), Melaka, Malaysia. Email: fariz@utem.edu.my

Junior Sintar, Mechatronics Department, Faculty of Electrical Engineering, Universiti Teknikal Malaysia Melaka (UTeM), Melaka, Malaysia.

Mohd Shahrieel Mohd Aras, Mechatronics Department, Faculty of Electrical Engineering, Universiti Teknikal Malaysia Melaka (UTeM), Melaka, Malaysia.

Ahmad Zaki Shukor, Mechatronics Department, Faculty of Electrical Engineering, Universiti Teknikal Malaysia Melaka (UTeM), Melaka, Malaysia.
The electrical properties from the muscles are also known as myoelectric signals. The myoelectric signals are commonly used to control assistive devices such as robotic arm, exoskeleton and prosthetics. EMG is widely used because it provides an easy and natural sensation in controlling over the devices. According to [3], around 160,000 individuals requires prosthetic or orthotic devices in Malaysia. It is also stated in [4] that prosthetics is widely used in America and Russia, with an estimated number of amputation reaching 1.7 million people. The development of the EMG based device relies greatly on the EMG signals acquisition.

The EMG signals are detected by using electrodes which can be collected using two methods [5]; invasive and noninvasive. The invasive method uses wired electrode that is inserted inside the skin. The non-invasive method uses surface electrode that is placed on the surface of the skin. The surface electrode has been a more popular approach for research because the method is more convenient. A limitation exists for the surface EMG. It is due to the electrode records muscle activity through fascia, fat and skin which reduce physiological interpretation. However, this can be overcome using conventional signal processing method.

For a controller to be able to classify the signal properly, the characteristic of the EMG signal should be defined. There are three important stages [6] for a successful EMG signal classification which are pre-processing, feature selection and the classification. Noise, distortion and artifacts cause disturbance in the sample which diminish the quality of the signal. Filters are commonly used to remove the disturbances in the signal. The filter removes specific frequency that does not provide important features for signal classification.

In this paper, methodology used in this project will be explained in section II, result and discussion in section III and finally conclusion in section IV.

\section{METHODOLOGY}

This section consists mainly of the tasks and experiments conducted in this project. There are three tasks in total which are the robotic arm hardware development, development of forward kinematic of the robotic arm, sensor calibration and electrode positioning. There are a few possible experiments able to perform by the system but in this paper only one experiment will be presented, known as EMG signal classification test. 


\section{DESIGN AND CONSTRUCTION OF 4-DOF EMG-BASED ROBOT ARM SYSTEM}

\section{A. Task 1: Robotic Arm Hardware Development}

This section will discuss on the servo motor, Arduino Uno, Myoware muscle sensor, robotic arm, robotic arm circuit design and robotic arm source code development. The function and specification of each component are explained thoroughly.

Servo motors are suitable for robotics arm because it has decent torque and precise control over angular rotation. The servo motors are controlled by sending pulse width modulation (PWM) through the control wires. The connection mount consists of three inputs which are positive supply, ground and signal. The robotic arm constructed in this project used four types of servo motors which are SG90, Futaba S3003, MG946R and two HD 1501 MG as shown as in Fig. 1. Table I shows the specification of the servo motors used.

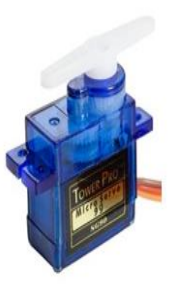

(a)

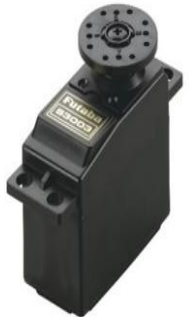

(b)

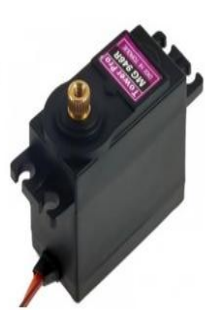

(c)

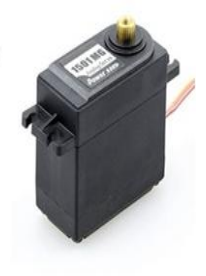

(d)
Fig.1.Types of servo motor (a) SG90 (b) Futaba S3003 (c) MG946R (d) HD1501 MG.

Table- I: Specification of servo motor

\begin{tabular}{|c|c|c|c|c|}
\hline Specification & SG90 & $\begin{array}{l}\text { Futaba } \\
\text { S3003 }\end{array}$ & MG946R & HD1501MG \\
\hline $\begin{array}{l}\text { Operating } \\
\text { Voltage }\end{array}$ & $+5 \mathrm{~V}$ & $+5 \mathrm{~V}$ & $+5 \mathrm{~V}$ & $+6 \mathrm{~V}$ \\
\hline Torque & $2.5 \mathrm{~kg} / \mathrm{cm}$ & $4.1 \mathrm{~kg} / \mathrm{cm}$ & $13 \mathrm{~kg} / \mathrm{cm}$ & $17 \mathrm{~kg} / \mathrm{cm}$ \\
\hline Gear Type & Plastic & Plastic & Metal & Metal \\
\hline Rotation & $0^{\circ}-180^{\circ}$ & $0^{\circ}-180^{\circ}$ & $0^{\circ}-180^{\circ}$ & $0^{\circ}-180^{\circ}$ \\
\hline Weight & $9 \mathrm{~g}$ & $37 \mathrm{~g}$ & $55 \mathrm{~g}$ & $60 \mathrm{~g}$ \\
\hline $\begin{array}{l}\text { Current } \\
\text { (idle) }\end{array}$ & $\begin{array}{l}5 \mathrm{~mA} \\
(4.8 \mathrm{~V}) \\
6 \mathrm{~mA} \\
(6 \mathrm{~V})\end{array}$ & $\begin{array}{l}7.2 \mathrm{~mA} \\
(4.8 \mathrm{~V}) \\
8 \mathrm{~mA}(6 \mathrm{~V})\end{array}$ & $10 \mathrm{~mA}$ & $\begin{array}{l}4 \mathrm{~mA}(4.8 \mathrm{~V}) \\
5 \mathrm{~mA}(6 \mathrm{~V})\end{array}$ \\
\hline $\begin{array}{l}\text { Current } \\
\text { (no } \\
\text { load) }\end{array}$ & $\begin{array}{l}100 \mathrm{~mA} \\
(4.8 \mathrm{~V}) \\
120 \mathrm{~mA} \\
(6 \mathrm{~V})\end{array}$ & $100 \mathrm{~mA}$ & $170 \mathrm{~mA}$ & $\begin{array}{l}400 \mathrm{~mA}(4.8 \mathrm{~V}) \\
500 \mathrm{~mA}(6 \mathrm{~V})\end{array}$ \\
\hline $\begin{array}{l}\text { Current } \\
\text { (stall current) }\end{array}$ & $\begin{array}{l}700 \mathrm{~mA} \\
(4.8 \mathrm{~V}) \\
800 \mathrm{~mA} \\
(6 \mathrm{~V})\end{array}$ & $<1000 \mathrm{~mA}$ & $1200 \mathrm{~mA}$ & $\begin{array}{l}2300 \mathrm{~mA}(4.8 \mathrm{~V}) \\
2500 \mathrm{~mA}(6 \mathrm{~V})\end{array}$ \\
\hline
\end{tabular}

In this project, the Arduino UNO Rev3 board has been used as the microcontroller of the system. This microcontroller is based on the Atmega32P. The board is commonly used in project as it is easy to upload and run programmer in the controller. The board runs on a $16 \mathrm{MHz}$ crystal oscillator and consists of mainly of 14 digital input/output pin, 6 analog inputs, USB input, reset button and power supply input. The I/O female header is provided to ease wire connection without the need of any soldering process. The Arduino UNO Rev 3 is an all-round microcontroller that is suitable for electronic projects.

The Myoware muscle sensor is used for this project because it is capable of measuring muscle activation in terms of electric potential. It is a single channel sensor which can be used to extract EMG signal from a single group of muscle. The sensor features a built-in electrode connector which makes the Myoware wearable. There are several shields that can be directly mounted on the module such as the power shield, cable shield, proto shield and LED shield. The sensor can produce two types of output which are amplified raw EMG signal and EMG envelope which has already been amplified, rectified and integrated. The adjustable gain potentiometer located on the module is used to adjust the gain of EMG signal. Fig. 2 shows the Myoware muscle sensor and Table II shows the specifications of Myoware muscle sensor.

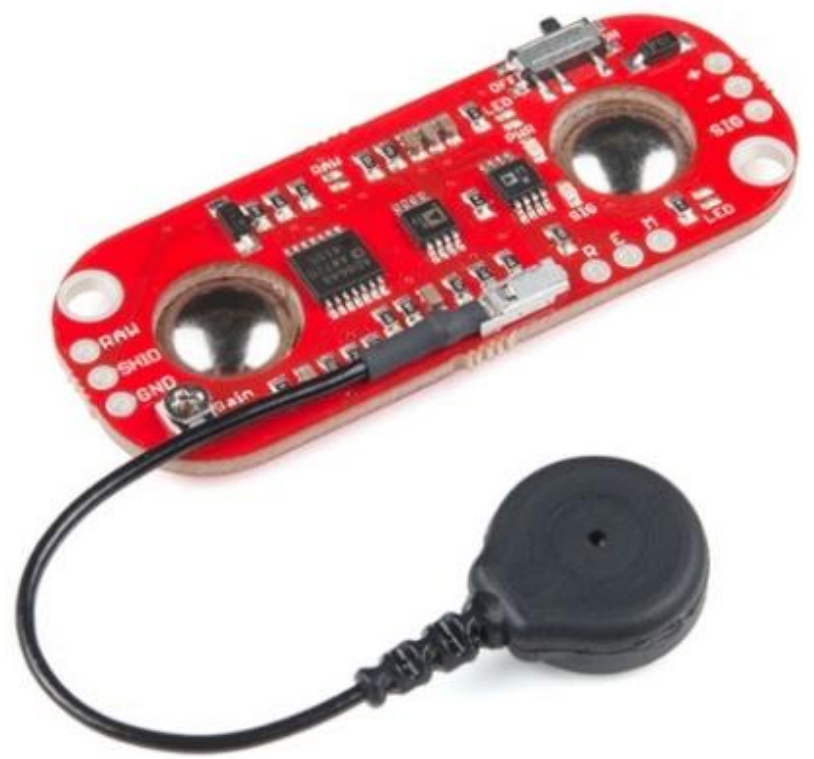

Fig. 2.Myorware muscle sensor.

Table- II: Specification of Myoware muscle sensor

\begin{tabular}{|l|l|l|l|l|}
\hline \multicolumn{2}{|l|}{ Parameter } & Min & TYP & Max \\
\hline Supply voltage & $+2.9 \mathrm{~V}$ & $\begin{array}{l}+3.3 \mathrm{~V} / \\
+5.5 \mathrm{~V}\end{array}$ & $+5.7 \mathrm{~V}$ \\
\hline \multicolumn{2}{|l|}{ Supply current } & - & $9 \mathrm{~mA}$ & $14 \mathrm{~mA}$ \\
\hline $\begin{array}{l}\text { Output } \\
\text { voltage }\end{array}$ & EMG Envelope & $0 \mathrm{~V}$ & - & $+\mathrm{Vs}$ \\
\hline \multicolumn{2}{|l|}{} & & & \\
\hline Input bias & EMG Raw & $0 \mathrm{~V}$ & - & $+\mathrm{Vs}$ \\
\hline
\end{tabular}

The robotic arm joints are connected by steel frames which have slots that fit the servo motor. The manipulator has a total of 4 degree of freedom not including the gripper. It has five type of rotation which is base rotation, shoulder rotation, elbow rotation, wrist rotation and gripper rotation. The servo motors are attached to each joint based on the amount of torque it can produce. Fig. 3 shows the representation of each joint with the arm motion.

The robotic arm designed and developed in this project has a total of two inputs (reset button, Myoware muscle sensor) and 6 outputs (servo motors, serial monitor). A 5V, 7A AC to DC power supply is used to power the servo motors. The Arduino UNO board is powered by a USB cable that is connected to the computer and the Myoware muscle sensor is connected to the $5 \mathrm{~V}$ supply pin on the board. Servo motor MG946R, HD 1501 MG, Futaba S3003 and SG90 are connected to pin D9, D10, D11, D12 and D13 respectively while the sensor is connected to analog pin A0. A reset button is prepared to reset the robot to its original position. Fig. 4 shows the circuit diagram of robotic arm.

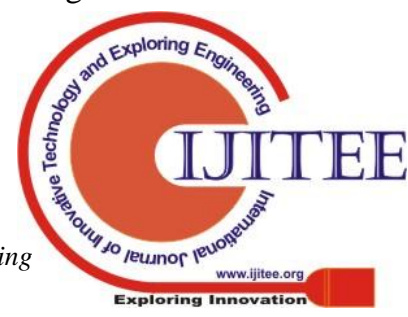




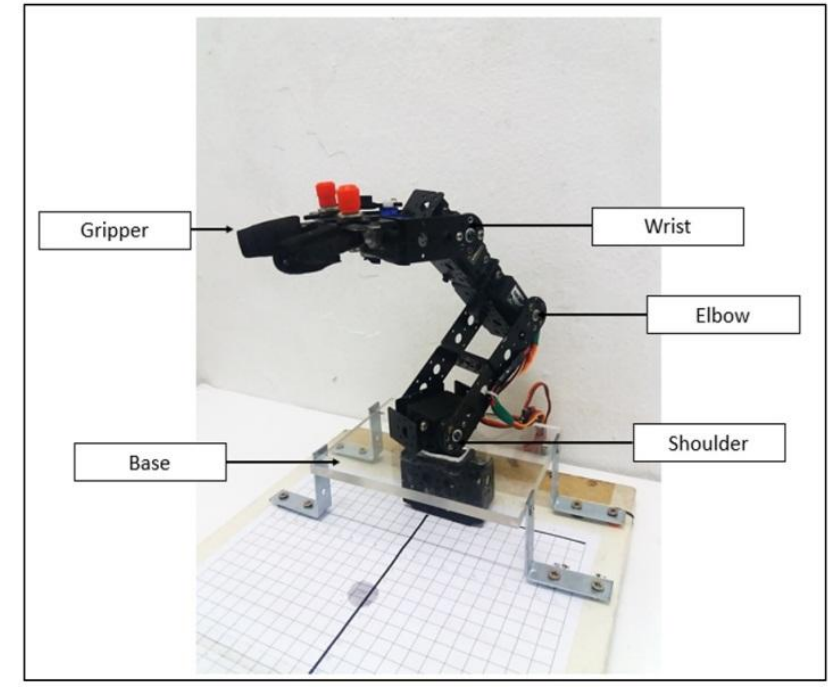

Fig. 3.Robotic arm designed.

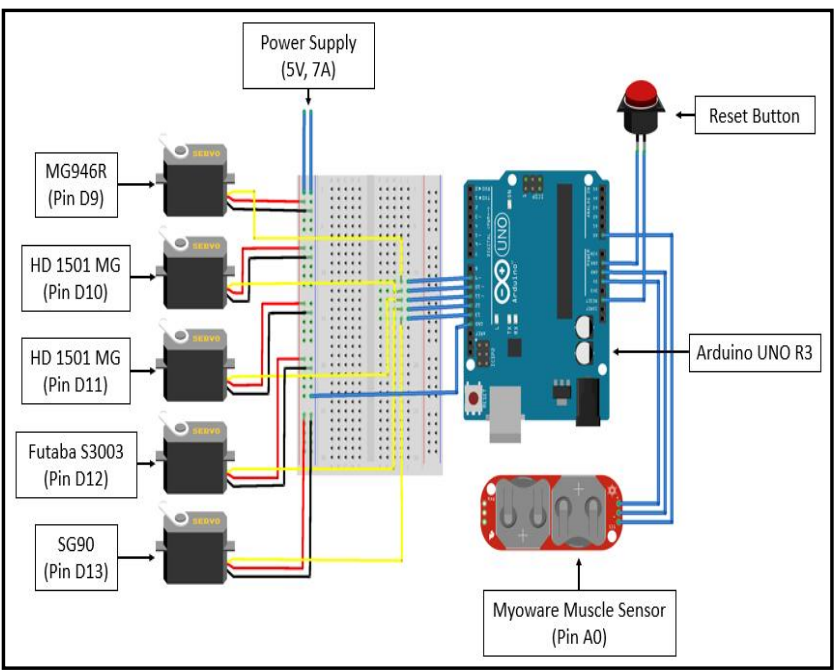

Fig. 4.Robotic arm circuit diagram.

The source code developed for the robot consists of two main subroutines which are the motor selection subroutine and motor run subroutine. Initially, the robotic arm will move to its original position which has already been preprogrammed and will return to its original position whenever the reset button is pushed. Hand gesture is used to navigate through the program window. For each function, the EMG signals value (bits) are read from the analog input of the controller. The value is printed on the serial window that enables the user to view it. The program is also able to read the final value of each angle of rotation of the servo motor in the motor selection subroutine.

B. Task 2: Developing the Forward Kinematic of 4-DOF Robotic Arm

The forward kinematic is used to obtain the coordinate of end effector and to determine the workspace of the manipulator. The angles rotation of each joint is used to compute the coordinate by using the transformation matrix equation. Fig. 5 shows the robotic arm with each of its joint labelled with axis.

The Denavit-Hartenberg (DH) parameter of the robotic is obtained by inserting the correct parameter in the $\mathrm{DH}$ parameter table. There are four parameters that needed to be considered. Table III shows the definition of each parameters.

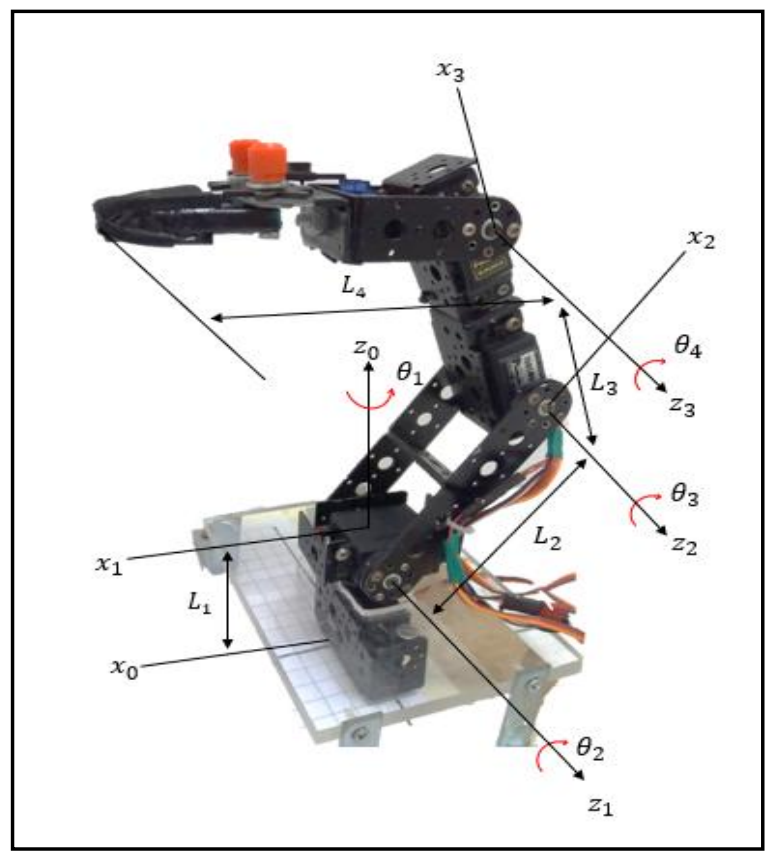

Fig. 5.Robotic arm circuit diagram

Table- III: DH parameters definition

\begin{tabular}{|l|l|}
\hline Parameters & Definition \\
\hline $\mathrm{d}$ & $\begin{array}{l}\text { The distance of the previous } \mathrm{x} \text {-axis to the } \\
\text { current } \mathrm{x} \text {-axis along the } \mathrm{z} \text {-axis }\end{array}$ \\
\hline$\theta$ & $\begin{array}{l}\text { The angle of rotation about the } \mathrm{z} \text {-axis between } \\
\text { the previous } \mathrm{x} \text {-axis to the current } \mathrm{x} \text {-axis }\end{array}$ \\
\hline $\mathrm{a}$ & $\begin{array}{l}\text { The length between the between the previous } \mathrm{z} \text { - } \\
\text { axis to the current } \mathrm{z} \text {-axis along the } \mathrm{x} \text {-axis }\end{array}$ \\
\hline$\alpha$ & $\begin{array}{l}\text { The angle of rotation about the } \mathrm{x} \text {-axis between } \\
\text { the previous } \mathrm{z} \text {-axis to the current } \mathrm{z} \text {-axis }\end{array}$ \\
\hline
\end{tabular}

By referring to Fig. 5, the DH parameters of the 4-DOF robotic arm are developed. Table IV shows the DH parameters of the manipulator. The parameters are then inserted into (1) which is the general formula of transformation matrix. The ${ }_{4}^{0} T$ matrix is obtained as show in (2). Cos and sin are substituted with c and s respectively to simplify the equation.

Table- IV: DH parameter of 4-DOF robotic arm

\begin{tabular}{|c|r|r|r|r|}
\hline $\begin{array}{c}|c| \\
(i)\end{array}$ & $\theta_{i}$ & $\alpha_{i}$ & $a_{i}$ & $d_{i}$ \\
\hline 1 & $\theta_{1}$ & 9 & 0 & $L_{1}$ \\
\hline 2 & $\theta_{2}$ & 0 & $L_{2}$ & 0 \\
\hline 3 & $\theta_{3}$ & 0 & $L_{3}$ & 0 \\
\hline 4 & $\theta_{4}$ & 0 & $L_{4}$ & 0 \\
\hline
\end{tabular}

${ }_{\mathrm{i}}^{\mathrm{i}-1} T=\left[\begin{array}{cccc}\cos \theta_{i} & -\sin \theta_{i} \cos \alpha_{i} & \sin \theta_{i} \sin \alpha_{i} & a_{i} \cos \theta_{i} \\ \sin \theta_{i} & \cos \theta_{i} \cos \alpha_{i} & -\cos \theta_{i} \sin \alpha_{i} & a_{i} \sin \theta_{i} \\ 0 & \sin \alpha_{i} & \cos \alpha_{i} & d_{i} \\ 0 & 0 & 0 & 1\end{array}\right](1)$

Published By: 


\section{DESIGN AND CONSTRUCTION OF 4-DOF EMG-BASED ROBOT ARM SYSTEM}

$$
{ }_{4}^{0} T=\left[\begin{array}{cccc}
c_{1} c_{123} & -c_{1} s_{234} & s_{1} & c_{1}\left(L_{2} c_{2}+L_{3} c_{23}\right)+L_{4} c_{1} c_{234} \\
s_{1} c_{123} & -s_{1} s_{234} & c_{1} & s_{1}\left(L_{2} c_{2}+L_{3} c_{23}\right)+L_{4} s_{1} c_{234} \\
s_{234} & c_{234} & 0 & L_{1}+L_{2} s_{2}+L_{3} s_{23}+L_{4} s_{234} \\
0 & 0 & 0 & 1
\end{array}\right]
$$

\section{Task 3: Sensor Calibration and Electrode Positioning}

The sensor preparation is important to get a good reading of EMG signals from the muscle. The sensors need to be placed in the center of the selected muscle which in this project is the Flexor digitorumsuperficialis (FDS) muscle is chosen. Fig. 6 shows the area of FDS muscle and the position of each electrode. The gain potentiometer can be calibrated after placing the electrode using a screwdriver.

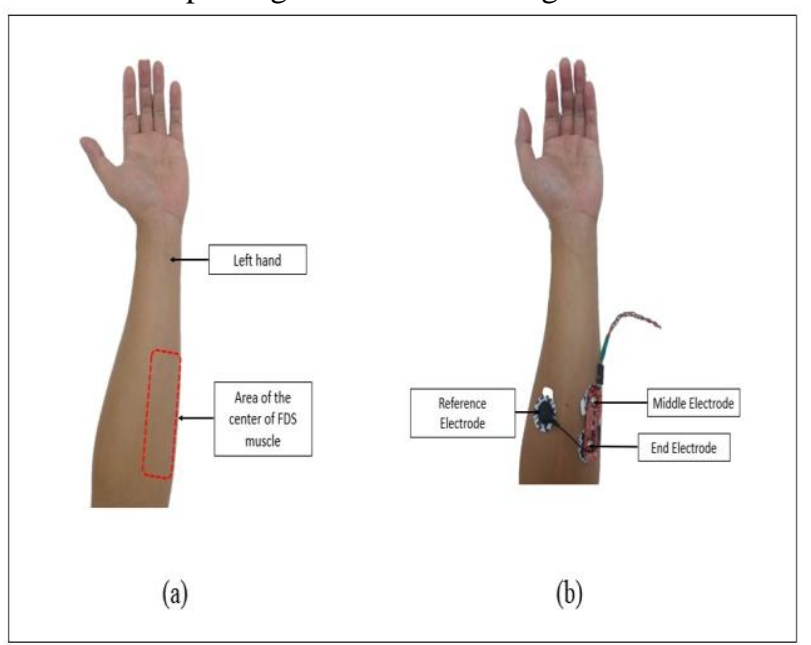

Fig. 6.Placement of EMG sensor (a) area of placement (b) electrode positioning.

Precaution needs to be taken before and after placing the electrode onto the skin as this will affect the signal output of the sensor. The excess oil from the skin needs to be cleaned. The usage of a hand sanitizer is able remove the oil. Thin hair on the arm should be shaved to add more contact between the electrodes with skin. The body needs to be properly isolated from the floor to reduce the noise. The usage of Velcro tape is advisable as it can help secure the sensor in place. Avoid using the sensor in a warm room as it will cause the skin to sweat. Instead, a well air-conditioned room can help the adhesive to stick better. The laptop charger needs to be unplugged from the laptop if the signal is unstable.

\section{Experiment: EMG Signal Classification Test}

The aim of this experiment is to determine the EMG signal produced by different types of gestures and choose the best gesture which can be used to control the robotic arm. In addition, this experiment focuses on partly achieving the objective of this project which is to perform analysis on the operation of the robotic arm based on the characteristic of EMG signal collected from the forearm. For this test, nine hand gesture have been used which are hand rest, thumb flex, index finger flex, middle finger flex, ring finger flex, little finger flex, wrist extension, wrist flexion and grasping. The gestures are performed to produce EMG signals value (bits) which is recorded by the serial monitor. 20 samples are taken for each of the gesture. The graph of the EMG signals is plotted and classified.

The components and equipment used for this experiment are Arduino UNO Rev3, Myoware muscle sensor, USB cable and laptop. The connection scheme is shown in Table V. The circuit diagram and experiment are shown in Fig. 7 and 8 respectively.

Table- V: Experiment connection scheme

\begin{tabular}{|c|c|c|}
\hline & Input / Output & Connection \\
\hline \multirow[t]{4}{*}{1.} & Arduino pin & \\
\hline & $\begin{array}{ll}\bullet & +5 \mathrm{v} \\
\text { supply } & \end{array}$ & $\begin{array}{l}\text { Connected to supply wire of } \\
\text { Myoware muscle sensor }\end{array}$ \\
\hline & Ground & $\begin{array}{l}\text { Connected to ground wire of } \\
\text { Myoware muscle sensor }\end{array}$ \\
\hline & Pin A0 & $\begin{array}{l}\text { Connected to servo motor data } \\
\text { wire }\end{array}$ \\
\hline 2. & $\begin{array}{l}\text { Arduino USB } \\
\text { Port }\end{array}$ & $\begin{array}{l}\text { Enable for power supply and for } \\
\text { viewing the serial monitor }\end{array}$ \\
\hline
\end{tabular}

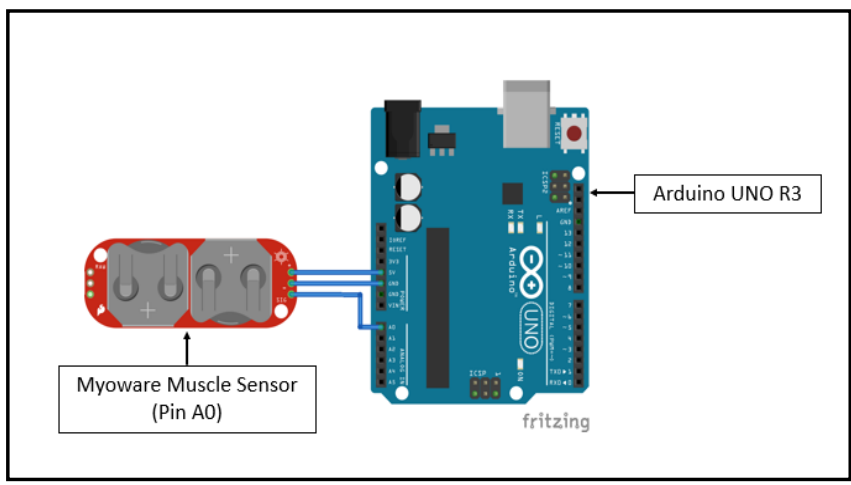

Fig. 7.Circuit diagram of experiment

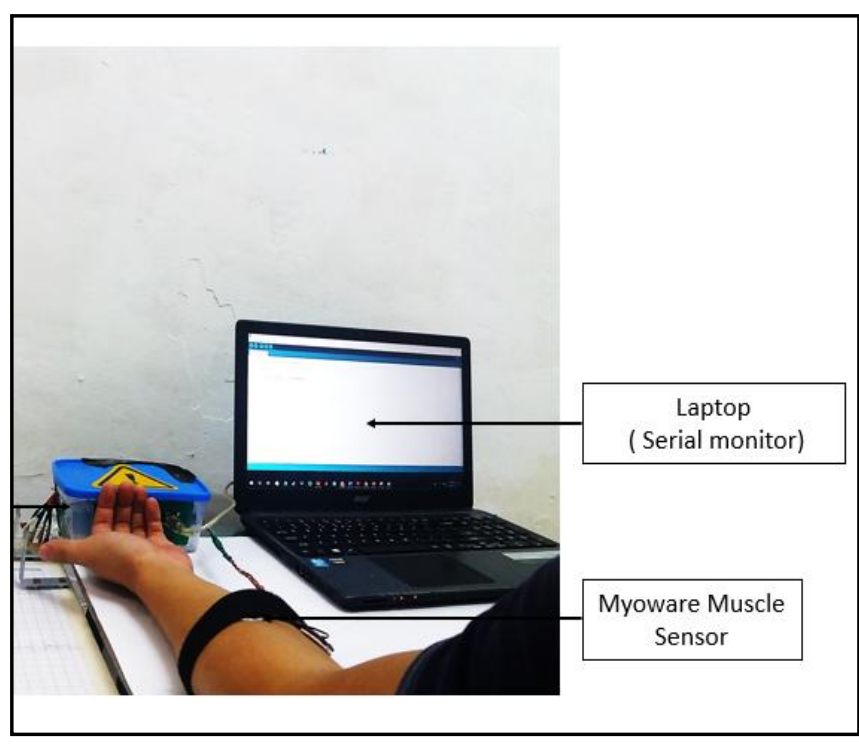

Fig. 8.Experiment setup.

The experiment is prepared as shown in Fig. 8. The Myoware muscle is placed on the forearm (FDS muscle) and the USB cable is connected to the Arduino Uno and the laptop. The elbow is rested properly on the table and the hand rest gesture is performed for 20 seconds. The reading is observed and recorded. The experiment is repeated with hand gesture thumb flex, index finger flex, middle finger flex, ring finger flex, little finger flex, grasping, wrist extension and wrist flexion. The gesture can be referred in Fig. 9. The EMG signals value(bits) is then tabulated into a table. 


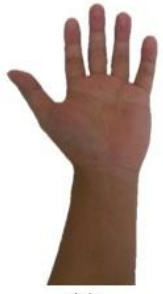

(a)

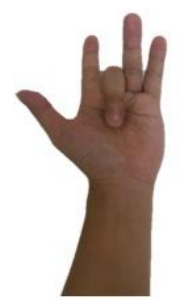

(d)

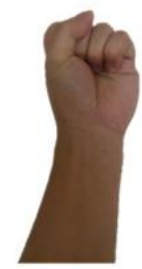

(g)

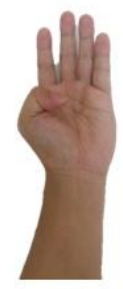

(b)

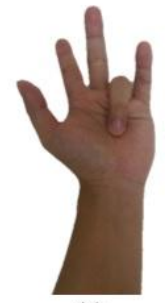

(e)

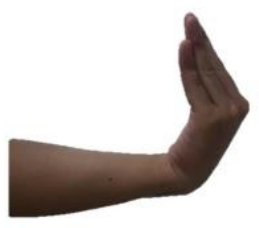

(h)

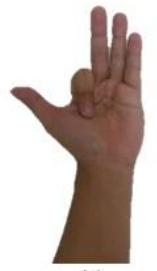

(c)

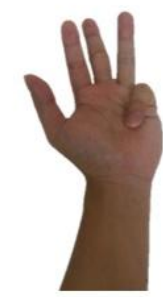

(f)

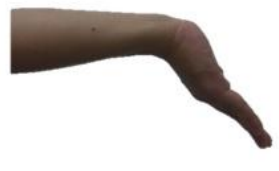

(i)
Fig. 9.Hand gestures (a) Hand rest (b) Thumb flex (c) Index finger flex (d) Middle finger flex (e) Ring finger flex (f) Small finger flex (g) Grasp (h) Wrist flexion (i) Wrist extension.

\section{RESULTS AND DISCUSSION}

In this section, results from experiment will be shown and discussed. Based on the experiment explained in the section before, data have been taken and graph is plotted as shown in Fig. 10.

Based on the graph in Fig. 10, the gesture which shows significant characteristic is the ring finger flex and grasping gesture. The ring fingers flex gesture value range from 70 90 bits while the grasping gestures range from 90-130 bits. Another gesture which shows a lesser significant is the wrist extension gesture which range from 50-60 bits. The other gestures are less than 55 bits. The usable gesture based on this experiment is gesture ring finger flex and grasping because the EMG signal can be differentiated from the rest of the gestures.

The grasping gesture can be divided into two gestures which is the medium grasp and hard grasp because the EMG signal depends on the amount force exerted by the action. In addition, both gestures are very comfortable and natural to perform. The wrist extension is not chosen because the EMG signal value is very near to the minimum value and is harder to perform. The rest gesture is also chosen to act as the normal position where no activation is occurred. Therefore, 4 gestures have been chosen out of the 10 gesture to control the robotic arm which are the hand rest, ring finger flex, medium grasp and hard grasp gestures.

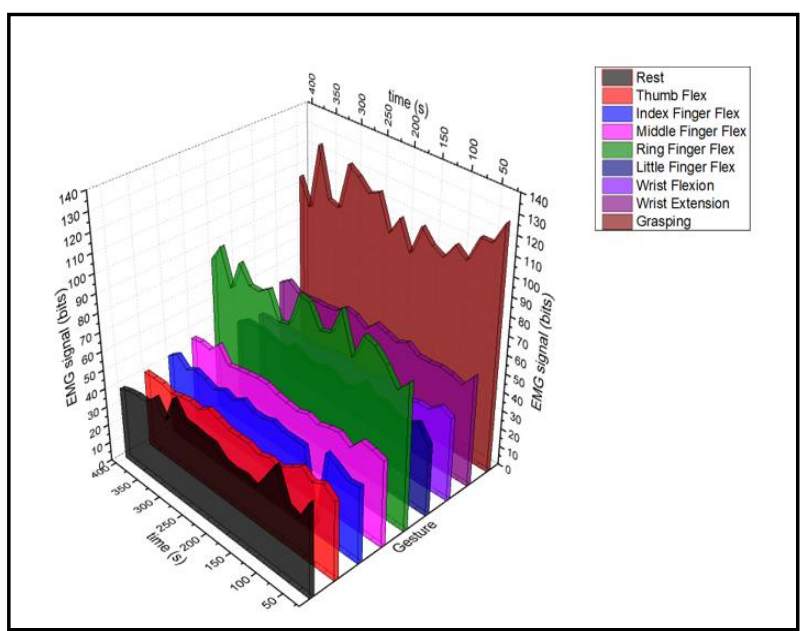

Fig. 10.Graph of EMG signalvs time.

\section{CONCLUSION}

It is shown in this paper that the objective to design and develop a functional 4-DOF EMG-based robotic arm has been achieved. The robotic arm is connected to the Myoware muscle sensor that sense EMG signals from the muscles. The manipulator can be controlled using hand gesture hand rest, ring finger flex, medium grasp and hard grasp to perform basic motion such as rotating joints and gripping objects. The joints can rotate to a specific angle using servo motors that is interfaced by the Arduino Uno R3. It is also shown in this paper that experiment known as EMG signal classification is done to perform analysis on the operation of the robotic arm based on the characteristic of EMG signal collected from the forearm. The hand gesture chosen generates different range value of EMG signals which later has been used to control the robotic arm joints. For future task, it is intended to add filters to smoothen the EMG signal in order to improve the overall performance of the robot arm system.

\section{ACKNOWLEDGMENT}

1. The authors wish to acknowledge the Ministry of Education, Malaysia and UniversitiTeknikal Malaysia Melaka, for supporting this research financially under CRIM.

\section{REFERENCES}

1 I. Elamvazuthi, N. H. X. Duy, Z. Ali, S. W. Su, M. K. A. A. Khan, and S. Parasuraman, "Electromyography (EMG) based classification of neuromuscular disorders using multi-layer perceptron," Procedia Comput. Sci., 76, 2015, pp. 223-228.

2 F. Sadikoglu, C. Kavalcioglu, and B. Dagman, "Electromyogram (EMG) signal detection, classification of EMG signals and diagnosis of neuropathy muscle disease," Procedia Comput. Sci., 120, 2017, pp. 422-429.

3 A. Nooranida, H. R. H, M. Hafiz, A. H. I, W. Afezah, and W. A, "Provision of prosthetic services following lower limb amputation in Malaysia," 24(5), 2017, pp. 106-111. 
4 L. S. Sudarsan and E. C. Sekaran, "Design and development of EMG controlled prosthetics limb," Procedia Eng., 38, 2012, pp. 3547-3551.

5 M. Jochumsen, A. Waris, and E. N. Kamavuako, "The effect of arm position on classification of hand gestures with intramuscular EMG," Biomed. Signal Process. Control, 43, 2018, pp. 1-8.

6 A. Boyali and N. Hashimoto, "Spectral collaborative representation based classification for hand gestures recognition on electromyography signals," Biomed. Signal Process. Control, 24, 2016, pp. 11-18.

\section{AUTHORS PROFILE}

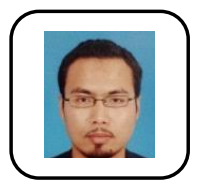

Fariz Ali obtained his highest education in Yokohama National University when he did his Doctor of Engineering in field of robotics in 2013 under supervision of Professor Atsuo Kawamura, the robotics expert from Japan. During his PhD study, DrFariz has develop the walking algorithm for bipedal walking robot by using Dual Length Linear Inverted Pendulum (DLLIPM) method. Earlier, Dr. Fariz has completed his master degree in University of South Australia, Adelaide in 2002-2004. He completed his undergraduate study at UniversitiTeknologi Malaysia in mechatronics engineering from 1998 to 2001 . He is currently working in Faculty of Electrical Engineering, UniversitiTeknikal Malaysia Melaka as senior lecturer. His research interest is humanoid robot, 6-legged robot, and other mechatronic project. He has successfully supervised 3 postgraduate students and about 25 undergraduate students for their final year projects. DrFariz has won three awards during the $26^{\text {th }}$ International Invention, Innovation and Technology Exhibition 2015 and one of the product is known as "RH2000 Cybernetics Hand". DrFariz has published articles more than 19 journal papers and 12 conference papers. In 2007, the Faculty of Electrical Engineering, UniversitiTeknikal Malaysia Melaka has recognized Dr. Fariz's contributions and services by giving him an award known as "AnugerahPerkhidmatanCemerlang" which is the excellence award for academician.

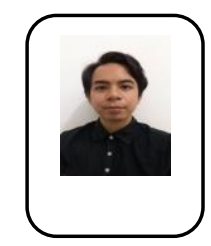

Junior Sintar personal profile which contains their education details, their publications, research work, membership, achievements, with photo that will be maximum 200-400 words.

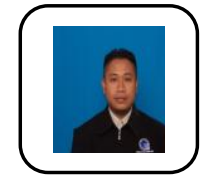

Dr. MohdShahrieelMohd Aras is an Associate Professor at Faculty of Electrical Engineering, UniversitiTeknikal Malaysia Melaka UTeM. His current research is focusing on control system design of underwater technology. His primary interests related to underwater robotics and Artificial Intelligence

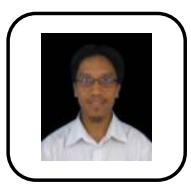

Ahmad ZakiShukorobtained his highest education in Yokohama National University when he did his Doctor of Engineering in field of robotics in 2012. Dr. Ahmad Zaki has completed his master degree in University of South Australia, Adelaide in 2002-2004. He completed his undergraduate study at UniversitiTeknologi Malaysia in mechatronics engineering from 1998 to 2001 . He is currently working in Faculty of Electrical Engineering, UniversitiTeknikal Malaysia Melaka as Associate Professor. 